\title{
LABELING OF CHEMICALS TO REDUCE RISK
}

\author{
SUSAN G. HADDEN*
}

I

\section{INTRODUCTION}

Of the fifteen or so major risk-abatement laws enacted during the 1970's, all except the ones pertaining to clean air and clean water require or permit labeling of hazardous products as one way of reducing risk to consumers and workers. Agencies have exercised their authorities to require labeling even when it is optional under the statute. Thus labeling is one of the most widely used regulatory techniques. The purpose of this article is to evaluate the efficacy of labeling potentially hazardous products containing chemicals as a means of controlling risk.

The argument of this article proceeds as follows: information is essential to assessment of risk and a decision to assume that risk; however, the market does not provide enough incentives to ensure that this information is produced. Thus government must intervene. The primary means that government has used to elicit risk information has been to require this information on labels of potentially hazardous products. Unfortunately, government response has been rather piecemeal, so that information provided on labels is inconsistent in format and, to a lesser extent, in risk level. People cannot effectively use the risk information made available by government intervention both because it is inconsistent and because too much information is provided. A uniform system of symbolic labels can alleviate this problem by providing people with first-order risk information, serving as a screening device for those who do not need the more detailed information now provided on labels. This article will discuss in turn the need for government intervention, current statutory mandates, and labeling practices, concluding with recommendations that might lead to the establishment of a more effective labeling system.

\section{II}

\section{Government Regulation OF Risk}

The regularity with which unanticipated and undesired side-effects accompany the adoption of new technologies has focused public attention on "risk" and on the possibility of its regulation by governments. Just like the technologies that cause them, these risks are identified, assessed, and mitigated only through increasingly sophisticated uses of scientific and technical information. Individuals and societies

Copyright (C) 1983 by Law and Contemporary Problems.

* Lyndon B. Johnson School of Public Affairs, University of Texas, Austin. 
that wish to reduce or avoid risks must assess risks and offsetting benefits of using or avoiding a particular technology and decide on the most favorable course. Information is thus inextricably intertwined with risk, both in its genesis and its control.

\section{A. Characteristics of Risk}

An ordinary language definition of risk makes clear the close connection between the concepts of risk and of information. "Risk" expresses some likelihood that something harmful or undesirable will occur, and so it is a joint consideration of probability and of adverse consequences." Consequences are in turn composed of two factors: the number of people affected (magnitude) and the exact nature of the consequences to those affected (severity). This definition highlights what must be done to control a risk: reduce its magnitude or severity or both. ${ }^{2}$

One of the most troublesome aspects of risk for many people is the extent to which certain involuntary or uncontrollable risks are unknowingly assumed. Indeed, these characteristics make people perceive such risks to be more risky than objectively similar risks that are assumed voluntarily or appear to be controllable. ${ }^{3}$ Many critics have pointed to the dangers of attempting to achieve a no-risk society, ${ }^{4}$ but those arguments are not relevant here. People do not seek complete eradication of risk; rather, they only want to be able to assume risks knowingly and willingly, as they already do in undertaking ordinary tasks every day. ${ }^{5}$

People accept risks because they estimate that the benefits of a certain act outweigh the given risks. For the risk to be assumed knowingly and willingly, the actor must have a substantial amount of information; ${ }^{6}$ at a minimum, he would like to know:

(1) That there is a risk;

(2) The probability and severity of the risk; ${ }^{7}$

(3) Benefits of the action;

1. On the importance of ordinary language for considerations of public policy, see R. FLATHMAN, The Public INTER EST xi-xiii (1966). For a very similar definition of risk, see Lowrance, The Nature of Risk, in Societal Risk Assessment: How Safe Is Safe Enough? 5, 5-14 (1980).

2. A program implemented by human beings cannot directly change the probability of a particular risk, but it can change the conditions so that everyone is in a different, more desirable state in which probabilities are lower. For example, in 1979, the probability of being killed in an auto accident was one in a million for each 300 miles driven. Wilson, Analyzing the Daily Risks of Life, 81 TECH. REV., Feb. 1979, at 40,45 . We cannot change that probability, given current conditions, but we could move to a different probability state by prohibiting driving while drunk or by requiring air bags.

3. Slovic, Judgment, Choice, and Societal Risk-Taking, in JUDGMENT AND DECISION-MAKING IN PUBLIC Policy Formation 98 (K. Hammond ed. 1978).

4. See, e.g., Crandall, Environmental Control is Out of Control, 57 CheM. \& ENG'G News 29 (1979); Wildavsky, No Risk Is the Highest Risk of All, 67 AMER. SCI. 32 (1979).

5. Wilson, supra note 2 , at $40-43$.

6. This means he is a rational actor. People have many habitual behaviors and make many decisions too minor to warrant obtaining all this information. When these behaviors entail risks, those risks are often being assumed unknowingly or are believed to be easily controlled. On the tendency to make decisions without resorting to elaborate decision models, see Olshavsky \& Granbois, Consumer Decision-Making: Fact or Fiction?, $6 \mathrm{~J}$. CONS. Research 93 (1979).

7. Its magnitude is probably not of interest. The actor is concerned with how likely it is to affect him, not its likelihood toward others. Magnitude will become of interest when there is social decisionmaking. 
(4) Alternate ways of obtaining the same benefits and the risks entailed by those alternative actions;

(5) How this risk compares to others;

(6) Whether he can reduce the risk by taking special precautions; and

(7) The risks of not undertaking the proposed action.

The very characteristics of risk, however, make this information difficult to obtain. While the probabilities in games of chance are subject to a priori or logical determination, the likelihood that health or the environment will be adversely affected by a particular act is not. In fact, ascertaining the probability distributions of a risk with any degree of confidence requires frequent experience with the adverse consequences; and even then the "measurement" of the probability remains an educated guess. Although we may attempt to simulate these risks through laboratory tests on animals, through computer models, or through epidemiological studies to determine the circumstances under which there will be direct effects on human health, many uncertainties will always remain.

Severity is equally difficult to measure. One common measure of toxicity, for example, is the LD50, the amount of a substance that is lethal to half the test animals within a specified time. Using a common metric, milligrams per kilogram of body weight, it is relatively easy to compare LD50's for various substances in laboratory animals. Extrapolation to humans, however, is not straightforward; one substance may affect humans in the same way as it affects rats but not dogs, another may do the opposite. Thus pharmaceuticals must be tested in three or four different species before they are approved for testing in humans. ${ }^{8}$ Even with such difficulties, the relative immediacy of the effect makes toxicity much easier to measure than effects that do not occur for many years; among the confounding effects are different individual sensitivities to exposure, possible interactive effects among substances, and, foremost, the absence of a model that shows how the causal agent produces the unwanted effect. ${ }^{9}$

The difficulties of measuring risks are exacerbated when it is necessary to compare them since this entails a tradeoff among the incommensurate dimensions of risks: probability, severity, and magnitude. The examples of automobile accidents and nuclear accidents suggest that many people are willing to accept a high probability, low consequence risk over a low probability, high consequence risk. The case, however, is less clear when the risk is of high probability among a very limited group, as with many occupational hazards, or of moderate probability and severity. ${ }^{10}$

Many of the attributes of risk that lead to problems in measurement also lead people to turn to government for risk control. For example, the unpredictability of

8. 3 Philosophy and Technology of Drug Assessment, The Philosophy of Evidence 93-97 (J. Cooper ed. 1972).

9. There is an extensive literature on the problems of determining long term health effects. One important assessment is found in OSHA's proposal for instituting generic regulations concerning carcinogens. See 41 Fed. Reg. 54, 156-61 (1977). For a shorter review, see Weisberger \& Williams, Carcinogen Testing: Current Problems and New Approaches, 214 SCIEnCE 401, 401-07 (1981).

10. On systematic biases in agency ranking of risks to overcome these difficulties, see Graham, Some Explanations for Disparities in Lifesaving Investments, I POL'Y STUD. REV. 692 (1982). 
many risks of new technologies has resulted in widespread adoption of innovations whose risks and benefits turn out to be distributed with an unacceptable degree of inequality. While both costs and benefits of some technologies-radiation emissions from color televisions or health effects of a risky treatment for an otherwise fatal disease, for example-accrue to the same individual, many more provide benefits to one group while posing risks to another group. The benefits of decreased food prices accrue to farm workers as well as to everyone else, of course, but virtually all the risks to humans of pesticide application fall on the farm workers. Government action is often used as a means for correcting externalities and maldistributions such as those created by many technological risks, especially when the risk is perceived as involuntary or uncontrollable by an individual. Thus people turn to government for protection from "unreasonable risk," 1 which they believe to be risks assumed without informed consent. ${ }^{12}$

The characteristics of risk discussed above also make it difficult to agree on public risk control programs: the distributional inequities subject decisionmakers to opposing pressures, while problems of measurement inhibit orderly selection among risks to be controlled. Thus, government risk control programs have tended to be ad hoc responses to particular crises rather than policies that reflect consideration of broader issues. These difficulties also lead policymakers to base risk control programs on provision of information to individuals who can then make risk decisions based on their own preferences.

Society can respond to risks by reducing the costs to each individual through risk spreading (insurance) or post hoc relief, as well as by reducing the magnitude or severity of risks. While such programs reduce the costs of risks to individuals, they do not mitigate the risks themselves. Labeling, however, is one of a series of regulatory measures intended to reduce the number of people affected or to attenuate directly the severity of the hazards they face. Labeling is supposed to accomplish this purpose by providing people with information about risks. The following section considers why this information is not available without government intervention.

\section{B. Information and Risk Control}

To perform properly, economic markets must meet several stringent conditions, including free entry for producers and full market knowledge for all actors. The latter condition, usually termed "perfect information," is never met in practice. One reason for this is that information itself is a commodity with a price. There is a point beyond which the gains from acquiring additional information are not offset by the costs, and economically rational actors therefore do not acquire full information.

11. This standard is embodied in several labeling laws, including the Federal Hazardous Substances Control Act, 7 U.S.C. $\S 1261$ (1976), and the Federal Insecticide, Fungicide, and Rodenticide Act, 7 U.S.C. $\S 136(1982)$.

12. Although the term "informed consent" has usually been limited to the practice of medicine, or by extension, to medical and other experiments involving human subjects, I believe that it exactly expresses the goal of most citizens who do complain about excessive risk in our society. See supra text accompanying note 3 . 
The need for government intervention in the market does not derive as much from these limits on information acquisition, however, as it does from problems with information production. Often, information constitutes a "public good"; that is, once it becomes available to some, it is difficult to prevent it from being used by others. Since those other users can obtain the information for free, they have no incentive to pay for it. Thus less information is produced than is "socially optimal" or would be used if available. One form of government response to this problem is patent and copyright law which attempts to prevent "free riders."

Other kinds of information would simply not be produced at all without public intervention. For example, consumers can act most efficiently when they can easily compare prices of comparable products through unit pricing. However, the time and energy that would be required for an individual consumer to make these comparisons is usually greater than the corresponding gain, although significantly less than the gains made by all consumers. If some outside agent, such as a government, forced the information to be made available and required each consumer to pay a very small portion of the cost of producing it, everyone would gain. The movement to get grocery stores to provide unit prices is an example of this kind of collective action; it was facilitated by the requirement in the Fair Packaging and Labeling Act ${ }^{13}$ that quantities be denoted on a package in consistent units and in a uniform location.

Providers of goods and services, who are in an especially favorable position to obtain and disseminate information about their products, may not be inclined to provide that information because it could encourage the consumer to choose a competitor's product. Thus government regulation is required to ensure that the generic name of the product appears on all drugs and pesticides, so that the consumer can make a ready comparison among products.

In addition to perfecting the market for information, government action may be necessary to ensure that the information is of a kind useful within the larger marketplace. Providers of information may deliberately deceive, ${ }^{14}$ and reliance on the courts for redress of injuries resulting from deception is both inefficient and inequitable. ${ }^{15}$ The first major statutory requirement for labeling in the United States, the 1906 Food and Drug Act, ${ }^{16}$ was designed to enable the government to hold manufacturers to claims by using the label as the enforcement standard. Present-day rules that prohibit pesticides from being named "Kill-All" or drugs from making claims of safety, prevent more subtle forms of deception. ${ }^{17}$ Information need not be deliberately deceptive. If the subject matter is complex or tech-

13. 15 U.S.C. $\S \S 1451-1461$ (1982).

14. See, for example, the evidence that the manufacturer knew of potential dangers to vision from continued use of its anticholesterol drug in Toole v. Richardson-Merrell, Inc., 251 Cal. App. 2d 689,60 Cal. Rptr. 398 (1967).

15. For several essays that suggest reliance on the courts, see SOCIAL REgulation: STRATEGiEs FOR REFORM (E. Bardach \& R. Kagan eds. 1982).

16. Ch. 3915, 34 Stat. 768 (1906) (current version at 21 U.S.C. $\$ 301$ (1976)).

17. On pesticides, which are also prohibited from making safety claims, see 40 C.F.R. $\S \S 162.10(\mathrm{a})(5)$ (ii) \& (x) (1982); on drugs, see 21 C.F.R. $\$ 201.10$ (c)(3) (1982). 
nical enough, provision of information can itself be confusing. ${ }^{18}$ Probabilistic data and related causal inferences that are needed for risk assessments fall into this category. One response to this problem is to reduce consumers' need to rely on complex information by limiting risks. Certification and licensing are government actions that ensure that products or practitioners have met some minimum standard of performance: Limits on filth in food are an example of this kind of regulation. Such regulation became more important with the advent of technologies, such as canning, that preclude easy inspection of a product before purchase.

In sum, information is a central element in a person's ability to reduce or take control over the decision to assume risks that confront him. Nevertheless, there is still a lack of proper information for two major reasons:

1. It is not available. This may be because information does not exist, is too expensive to obtain, or is deliberately withheld by its owner.

2. It is not accurate. This may occur because the information is falsified by the supplier, consists of irrelevant or misleading material, is poorly worded or confusing, or is incomplete.

In addition, information that is available may be difficult for consumers to understand or evaluate.

Thus there is justification for government intervention in the marketplace to provide information, especially risk information. Corresponding to the two barriers to use of information, there are two major roles that government can play in regulating it:

1. Ensure that information is available.

2. Ensure that information is accurate.

A third role, reducing the need for information through imposition of standards that ensure a certain level of safety before the product reaches the consumer, supplements regulation of information. ${ }^{19}$

Labels - the written, printed, or graphic matter attached to, in the package of, or otherwise closely associated with a product or substance ${ }^{20}$ - are the instruments most often chosen by the federal government to achieve the first two purposes. Labels are also usually affixed to apprise the user of compliance with certification or licensing standards. A brief history of statutes requiring labels illustrates the expansion in the kinds of information subject to federal regulation and underlines the fragmented and inconsistent manner in which labeling policy has been formulated and implemented.

18. Harris, Training Consumers About Misleading Advertising: Transfer of Training and Effects of Specialized Knowledge, in CURRENT IsSues AND RESEARCH IN ADVERTISING 105, 105-22 (1981).

19. In fact, success of a labeling program also requires that users act on the information they have received. Thus another role for government might be to ensure or require that information is used. (For pesticides, it is already against the law to use the product in a manner not permitted by the label.) This article does not consider the appropriateness of that role; rather the discussion is limited to a consideration of the government's role in ensuring that accurate information is provided since people will not be able to act in accord with the label if they cannot understand it.

20. The first part of this definition is from the Federal Food, Drug, and Cosmetic Act, 21 U.S.C. $\$ 321(\mathrm{k})$ (1976); it limits the definition to material on the immediate container of any article, but courts and agencies have included other closely associated materials within the definition of "label." 


\section{III}

\section{Statutory Mandates for LABEling}

The labeling provisions of seven of the major labeling laws are shown in Table 1 (see APPENDIX), arranged in chronological order of passage of the principal versions of the laws. Not shown in the table is the original version of the Insecticides Act of $1910^{21}$ since it is very similar in phrasing to the Food, Drug and Cosmetic Act of 1906. The table provides some insight into the evolution of labeling policy for chemicals.

Perhaps the most important change in the labeling statutes is the increasing concern for health and safety risks and the concomitant diminution in relative importance of reducing economic risks. This change was effected by increasing the range of information regarded as appropriate for government oversight, especially with regard to provision of information.

Early laws focused on reducing economic risk through accurate information. Any proposed government intervention in the economy, such as the labeling provisions of the Food and Drug Act of 1906, had to be justified as a means of perfecting the market. ${ }^{22}$ Although provision of information was understood to be a benefit of labeling, the real justification for federal labeling authority was the need to ensure the information's accuracy; labels would be used as an enforcement standard for deterring false claims, which constitute an unfair trade practice. Thus, the 1906 drug act and the 1910 insecticide act both required that labels provide an accurate list of ingredients and proportions, especially of active ingredients.

In 1911 and 1922 the Supreme Court upheld the constitutionality of labeling regulations under the Food and Drug $\mathrm{Act}^{23}$ and the Federal Trade Commission Act of $1914 . .^{24}$ In both instances the Court emphasized mislabeling as a form of unfair competition. ${ }^{25}$ Narrow laws such as the Wool Products Labeling Act of $1939,{ }^{26}$ the Textile Fiber Products Identification Act, ${ }^{27}$ and the Fur Products Labeling $A c t^{28}$ requiring labels to ensure the provision of accurate information as to product quality, continued to be enacted for decades. Like drugs, the products regulated by these laws are difficult for laymen to assess independently.

Governmental acts to inhibit unfair competition by ensuring accurate information aid consumers as well. However, many forms of direct assistance to consumers by making information available remained outside the boundaries of appropriate

21. Ch. 191, 36 Stat. 335 (1910) repealed by ch. $125, \S 16,61$ Stat. 172 (1947). This matter is presently covered by 7 U.S.C. $\$ 136$ (1982).

22. See, for example, the debate on that bill, 40 CONG. REC. 8889 (1906), and the Views of the Minority in the Report of the Committee on Interstate and Foreign Commerce, H.R. REP. NO. 2118, 59th Cong., 1st Sess. 14 (1906).

23. United States v. Johnson, 221 U.S. 488 (1911).

24. FTC v. Winstead Hosiery Co., 258 U.S. 483 (1922).

25. Uniled Slates $v$. Johnson emphasized the purpose of market protection by prohibiting the FDA from trying to hold producers to standards of efficacy implied by indications for use on drug labels, asserting that at the current state of pharmacy this was leading the government into the realm of uncertain knowledge. 221 U.S. at 497-98.

26. Ch. 871,54 Stat. 1128 (1940) (current version at 15 U.S.C. $\$ 68$; (1982)).

27. Pub. L. No. 85-897, 72 Stat. 1717 (1958) (current version at 15 U.S.C. $\$ 70(1982)$ ).

28. Ch. 298, 65 Stat. 175 (1951) (current version at 15 U.S.C. $\$ 69$ (1982)). 
government action set by court and public opinion. The 1960's marked the beginning of a period in which the acceptable scope of governmental activity was greatly enlarged. Consumer protection, for example, could be justified in quasimarket terms as redressing an imbalance in bargaining power between individual consumers and giant industries, or, in the emerging parlance of consumer and environmental activists, as emphasizing distributional justice and the public good. Thus the government's task-ensuring the availability and accuracy of information-remained the same, but the sphere of information that could be regulated was enlarged, especially in the area of information provision.

The nature of the change in governmental responsibility for information from the old kind of market regulation to the new consumer protection can be seen in the Truth-in-Lending Act. ${ }^{29}$ The act highlights a distinction between regulation of the accuracy of information that permits comparison among products and provision of information that indicates which characteristics are most important to compare. ${ }^{30}$ It requires that lenders provide borrowers with information about the true interest rate and total lifetime payments, not just the apparent interest rate. The Drug Amendments of 1962,31 which gave the FDA the power to enforce claims of efficacy as well as safety, also illustrate the increased scope of information being brought into the public arena.

One reason that people accepted the increased scope of government activity was the realization that information was becoming so complex that it was difficult to understand or act upon. This led in turn to the broader notion that some groups-children, for example-would never be in a position to use information effectively. Thus government had to act still more forcefully on their behalf, by prohibiting certain kinds of advertising, or by requiring installation of "childproof" caps on bottles. ${ }^{32}$ The environmental movement of the 1970's broadened the definition of helpless groups needing government protection to include the environment and future generations. In addition to expanding the types of information to be regulated, the period witnessed the growth of other kinds of regulatory techniques when provision of information alone was felt to be inadequate.

In the 1960's, then, there was a qualitative change from market protection, even in its broadened consumer protection interpretation, to a more direct emphasis on risk control. The first use of the label for risk control was concurrent with the market perfection use; the simple requirement in the 1906 Food and Drug Act that the amounts of certain dangerous ingredients be shown on the label was much stronger in laws concerning the practice of pharmacy in areas clearly subject to Federal control-Indian territories, ${ }^{33}$ Chinese consular districts ${ }^{34}$ and the Dis-

29. 15 U.S.C. $\$ \S 1601-1691$ (1982)

30. A. Grigsby, The Efficacy of the Consumer Information Disclosure Laws (Dec. 1979) (unpublished master's thesis, Univ. of Texas), makes this point, although he believes that "labeling" describes only regulation of accuracy, reserving "disclosure" for broadened information provision.

31. Pub. L. No. 87-781, 76 Stat. 780 (1962) (current version at 21 U.S.C. $\$ 321$ (1976)).

32. Federal Trade Comm'n, Staff Report on TV advertising to Children (1978) (children's advertising); Poison Prevention Packaging Act, Pub. L. No. 91-601, 84 Stat. 1670 (1970) (current version at 15 U.S.C. $\S \S 1471-1476$ (1982)) (child-proof caps).

33. Ch. 1806, 33 Stat. 550 (1904).

34. Ch. 74, 38 Stat. 817 (1915) (current version at 21 U.S.C. $\$ \S 201-202$ (1976)). 
trict of Columbia. ${ }^{35}$ These laws required that some twenty-five substances be labeled "POISON" and that pharmacists keep records naming people to whom they were dispensed. ${ }^{36}$ The Federal Caustic Poison Act of $1927,{ }^{37}$ passed when the evidence became incontrovertible that the states were not willing to make similar safety standards, 38 required the word "POISON" and directions for treatment of accidental ingestion to be placed on labels of the twelve substances named in the law.

The 1938 Food, Drug and Cosmetic $\mathrm{Act}^{39}$ is an important turning point in safety legislation in two ways. First, it provided for outright banning of substances that could not be adequately labeled, a significant risk control feature subsequently incorporated in laws regulating pesticides and consumer products. Second, labeling became entwined with registration of potentially hazardous products, so that the government began to regulate the wording of labels for specific substances rather than simply designating types of information to be provided. The Federal Hazardous Substances Control Act, ${ }^{40}$ passed in 1960 , extended the government's power to ban substances for which risk could not be satisfactorily reduced by labeling; it also provided for labels to indicate different levels of risk through the use of signal words. Furthermore, the act named specific technical standards for determining levels of risk high enough to warrant labeling for physical hazards such as toxicity, corrosiveness, and flammability.

The labeling and environmental protection laws passed since the middle 1960's pull together the two themes-reduction of economic risks and reduction of health and safety risks - and embody a very broad notion of governmental responsibility to parties (animate and inanimate) unable for various reasons to be equal actors in the economic market. The Resource Conservation and Recovery Act ${ }^{41}$ and the Toxic Substances Control Act ${ }^{42}$ seek to control a broad range of risks from toxic substances rather than focusing on risk victims as in earlier laws to protect air, water, or consumers. Although these laws are frequently considered to embody a "new social regulation,"43 their common characteristic is more their focus on side effects of new technologies and concomitant reliance on scientific and technical information that is complex and uncertain.

Although the purpose of the laws changed markedly, the label remained an important regulatory tool. Preservation of fair competition required that manufacturers state contents accurately. At about the same time, early hazard control laws defined the area in which information had to be provided simply by requiring the statement "POISON." Expanded consideration for consumer protection increased the kinds of claims requiring accuracy, including claims of efficacy, and

35. Ch. 2084,34 Stat. 175 (1906).

36. Ch. $74, \S 7,38$ Stat. 817,820 (1915); ch. 2084, § 13, 34 Stat. 175, 180 (1906); ch 1806, §14, 33 Stat. 550, 553 (1904).

37. Ch. 489, 44 Stat. 1407 (1927) (repealed 1960).

38. 67 CONG. REC. $6785-86$ (1926).

39. Ch. 675,52 Stat. 1040 (1938) (current version at 21 U.S.C. $\$ 136$ (1976)).

40. Pub. L. No. 86-613, 74 Stat. 372 (1960) (current version at 15 U.S.C. $\$ 1261$ (1982)).

41. 42 U.S.C. $\$ \S 6901-6987$ (1976).

42. 15 U.S.C. $\$ \$ 2601-2629$ (1982).

43. Lilley \& Miller, The New 'Social Regulation'; Public INTEREST, Spring 1977, at 47, 49-61. 
it even extended to requirements that weight be expressed in readily comprehendable and comparable units or that labels contain affirmative statements of qualities such as "imitation." Increasing attention to safety brought requirements for labels to describe antidotes for hazards as well as a broadened definition of hazards that must be mentioned.44 Finally, labels had to provide detailed instructions for use and for avoiding hazards, and in the case of drugs and pesticides, labels came to provide the licensing agreement between manufacturer and government.

The broadening of governmental power to regulate information thus led to the requirement that more and more kinds of information be provided on labels. At the same time, the broadening of governmental power on behalf of workers, consumers, the disadvantaged, and the environment meant that more and more kinds of products had to be labeled and that more agencies administered labeling programs. At present, at least seven federal and fifty state agencies oversee labeling programs. The most egregiously overburdened labels, pesticide labels, may be booklets of seventy or more pages.

As labeling became a strategy for controlling health risks, however, regulators found that they could not verify the accuracy of information about risks directly, as they could do with information about weights and contents. They therefore requested more and more information from producers, not for presentation on the label, but to form the basis for labeled information. This opened the way for negotiations between the regulators and the regulated about label content. ${ }^{45}$ Labeling became a means for forcing the generation of new information, rather than, as in the earlier laws, merely a way of forcing manufacturers to disclose accurate information they already possessed. The uncertainties inherent in measuring health risks fundamentally altered the nature of information regulation by the government, resulting in the intrusion of government regulation into the conduct and interpretation of laboratory experiments and epidemiological studies. The full implications of this change are not yet clear.

The change in emphasis in the purpose of labels did not cause information designed to reduce health and safety risks to replace information designed to reduce economic risks; rather, it caused more information to be added to the label. The tendency to add information to the label was exacerbated by its "supply-side" characteristic. ${ }^{46}$ Agencies were safer providing more rather than less information in the absence of a clear knowledge of who would be reading the label and what information would be especially appropriate. Most new risk control laws incorporated a labeling requirement because labeling functions as a comparatively benign form of regulation; it is relatively low in cost and it is able to preserve flexibility of action for the individual. Few of the statutory labeling requirements, however,

44. Both purposes were served by the ability of agencies to ban substances that were too hazardous to be labeled effectively.

45. On this process for drugs, see S. HADDEN, DES AND THE FDA: THE USEs Of TeChNICAL AdVICE in Regulatory Policy-Making 16 (1976) (describing FDA practice); P. Temin, Taking Your Medicine, Drug Regulation in THE United States (1981).

46. For this term and for a useful discussion of this point with respect to Environmental Impact Statements, see O'Hare, Information Management and Public Choice, in 1 Research in Public POLICY ANALYSis AND MANAGEMENT 226, 245 (J. Crecine ed. 1981). 
provided any guidelines about the forms of the labels or the specific levels of risk to be denoted. Agencies were given considerable leeway in these regards. From a common trunk-the laws of 1906 and 1910 - the various labels thus branched off to form a complex and internally inconsistent system.

\section{IV}

\section{LABELING OF Chemicals}

Risk-control programs are often formulated in response to a particular crisis. The laws requiring labeling are no exception. The result is predictably a fragmented and often inconsistent set of labeling requirements administered by various agencies. This section substantiates these contentions by a review of the labeling regulations that apply to chemicals throughout the production process: in the workplace, in transit, and at the final point of use. Table 2, discussed at the end of the section, provides a summary of some of the more detailed descriptions of label requirements.

\section{A. Labeling of Chemicals in the Workplace}

The intensity of employees' exposures to chemicals in the workplace led to early recognition of their need for help in controlling associated risks. Because the risks from improper handling are so high, workers have a strong incentive to learn how to control them. At the same time, there are limits on how many resources they must invest in acquiring information since most workers handle only a few substances. Provision of information about risks and risk control should therefore be an effective technique for occupational hazard reduction.

In 1934, the Surgeon General of the United States appointed a Chemical Products Agreement Committee to review the wording of labels to be used to indicate dangers of chemicals to workers. From that time until 1952, individual firms entered into agreements with the government about the kinds of warnings that they would use. In 1944, the Labels and Precautionary Information (LAPI) Committee of the Manufacturing Chemists Association (MCA) was formed. The committee published its first guide to labeling of hazardous chemicals in 1946; there have been six revisions since. In 1952, these guidelines replaced the agreements between individual firms and the Surgeon General. In 1976, the then current MCA-LAPI manual was adopted as an official standard of the American National Standards Institute (ANSI). ${ }^{47}$

These standards, developed with rigorous review procedures by groups with strong technical expertise, remain voluntary. ${ }^{48}$ The labeling standards mark an important step forward both in providing warnings to workers and in standardizing those warnings. The fact that many formal regulations embody the same standards testifies to their appropriateness for risk control. The effectiveness of

47. Historical background is found in MCA-LAPI MANUAL L-1 7-8 (7th ed. 1970). (I am indebted to the MCA - now the CMA-for allowing me to read the early versions of Manual L-1.)

48. On the role of voluntary standards in the United States, see R. Hamilton, Role of Nongovernmental Standards in the Development of Mandatory Federal Standards Affecting Safely and Health, 56 TEX. L. REV. 1329 (1978). 
voluntary labeling programs depends, of course, on their widespread adoption. An informal EPA survey, however, found that none of the small firms surveyed and only twenty percent of the larger firms use labels that tell specific chemical names rather than trade names, a feature clearly endorsed by the ANSI standard. ${ }^{49}$ The voluntary nature of the labels thus leaves room for flexibility, or, from a different standpoint, for inconsistency.

The 1982 ANSI standard has another feature with important implications for labeling as a risk control program; it is limited to acute hazards. As noted, there are important differences between risks which have immediate effects (acute hazards) and those in which effects may not be felt for many years (long term hazards). Long term hazards are more difficult to measure and at the same time are not considered as serious as objectively similar, acute risks. ${ }^{50}$ The degree of acute hazard of a chemical is often a function of its physical characteristics, such as the way in which it mixes with water or the minimum temperature at which a liquid gives off vapor in sufficient concentration to ignite (the flashpoint ${ }^{51}$ ). Given the ease of observing the results and the relatively long experience with measuring physical characteristics, it is not surprising that the first standards concentrated on these features, especially flammability and explosiveness. The warning "POISON" was to be applied to substances that killed half the experimental animals within forty-eight hours at doses of fifty milligrams per kilogram of body weight or less. ${ }^{52}$ Although many of the definitions have been refined over nearly four decades, and many new characteristics have been added, labels suggested by the voluntary standards still primarily address acute effects. ${ }^{53}$ Figure 1 shows some typical labels for acute effects; they include a warning (signal) word, description of the hazard, and prescriptions for risk-minimizing behavior.

Voluntary standards for labeling of chemicals in the workplace are supplemented by mandatory regulations issued by the Occupational Safety and Health Administration (OSHA). As of August, 1982, OSHA had two kinds of label requirements; a more general and uniform set of regulations was proposed March 19, 1982.54 The first kind are specific to particular chemicals, twenty-one of which are listed and described in the regulations. ${ }^{55}$ These specify that signs be posted in areas in which the chemicals are in use and that labels be affixed to containers of

49. Office of Pesticides and Toxic Substances, U.S. Environmental Protection Agency, Analysis of Present Labeling Practices (unpublished manuscript), cited in Occupational Safety and Health Administration, Draft Regulatory Impact Analysis and Regulatory Flexibility Analysis of the Hazard Communication Proposal 43 (Mar. 1982) (unpublished manuscript) [hereinafter cited as OSHA Draft Analysis].

50. Slovic, supra note 3 .

51. This definition is taken from Chemical Manufacturers Association, American National. Standard for the Precautionary labeling of Hazardous Industrial Chemicals 8 (1976).

52. MCA-LAPI ManUal L-1 13-14 (2d ed. 1949). Other numbers are provided for poisoning by inhalation and skin contact as well as for substances that are corrosive to human tissue or are sensitizers. The definitions for "flammable" and "extremely flammable" substances were drawn by the committee from the defintions used by the Interstate Commerce Commission.

53. The proposed revision of the ANSI standard would incorporate some labels for chronic effects. Interview with Manufacturing Chemists Association (July 1982).

54. 47 Fed. Reg. 12,092 (1982).

55. 29 C.F.R. $\S 1910.1000$ (1982). 
FIGURE 1

\section{HAZARDS:}

Highly Toxic by Ingestion

Toxic by Absorption

\section{DANGER! MAY BE FATAL IF SWALLOWED} HARMFUL IF ABSORBED THROUGH SKIN

Avoid contact with eyes, skin, and clothing

Wash thoroughly after handling.

\section{POISON $?$}

FIRST AID: If swallowed, induce vomiting by sticking finger down throat or by giving soapy or strong salty water to drink. Repeat until vomit is clear. Never give anything by mouth to an unconscious person.

In case of contact, immediately flush eyes or skin with plenty of water for at least 15 minutes while removing contaminated clothing and shoes. Wash clothing before reuse. (Discard contaminated shoes.)

\section{HAZARD: \\ Toxic by Inhalation}

\section{WARNINGI HARMFUL IF INHALED}

Avoid breathing (dust, mist, vapor, gas).

Keep container closed.

Use with adequate ventilation.

FIRST AID: If inhaled, remove to fresh air. If not breathing give artificial respiration, preferably mouth-to mouth. If breathing is difficult, give oxygen. Call a physician.

Source: Chemical Manufacturers Association, American National Standard for the Precautionary Labeling of Hazardous Industrial. Chemicals, app. (1976) (not part of official standard).

the substance. Only two of the substances are not carcinogens. All the others require similar notices stating that there is a "cancer-suspect" agent in the area and suggesting protective clothing or minimal exposure. Asbestos, not required to be labeled as a carcinogen, must bear a "CAUTION" sign, while lead present in more than specified concentrations must be labeled "POISON." Three of the substances require notification that respirators are needed, and several require labeling of contaminated work clothing. Five substances require the use of substance data sheets, which workers can consult for full details on possible hazards of exposure.

In addition, OSHA specifies a more general "safe color code" in which red stands for "stop" or "danger" or indicates the need for fire protection equipment 
and yellow indicates caution and warns against potential physical hazards. The paucity of OSHA regulations on labeling of hazardous substances reflects not only scientific uncertainties about the risks of exposure to many substances and the slowness with which a Standards Completion Program has been implemented, ${ }^{56}$ but also perhaps the prevalence of the voluntary standards.

In a survey conducted in 1974, the National Institute of Occupational Safety and Health (NIOSH) found that individual employees could potentially be exposed to as many as 1000 hazardous substances within a single establishment. At the same time, only three percent of employers were found to maintain comprehensive industrial health programs. ${ }^{57}$ To meet what it saw as a compelling need for more complete information about risks of exposure to hazardous substances in the workplace, OSHA proposed a more general labeling policy that would not have required issuing specific label wordings substance by substance. ${ }^{58}$ The program would have covered all manufacturers and would have required, among other features, identification of each chemical with its technical and common name and Chemical Abstract Service number and appropriate hazard warning labels for each container in the workplace. This proposal was withdrawn by the Reagan Administration. The labeling program promulgated in its place emphasizes "hazard communication rather than the identification of chemicals," with enough information provided to allow an employee to obtain more detailed data by referring to a Material Safety Data Sheet (MSDS). ${ }^{59}$ The program also emphasizes training in the workplace. Since the rules apply to "hazardous materials," defined to include acute physical hazards as well as health hazards both acute and chronic, the new regulations significantly increase the number of chemicals covered while reducing the amount of actual label content specified by the agency.

Since many materials shipped out of a manufacturing plant are destined for further industrial use, there are many advantages to a uniform system of workplace labels. The new regulation does not require consistent labeling, although it does specify that hazard labels remain on containers shipped out of the factory. ${ }^{60}$

The potential problems created by systems tailored too closely to needs of particular industries are illustrated by another voluntary hazard labeling program adopted by an industry intermediate in the manufacturing chain. The National Paint and Coatings Association has developed a Hazardous Materials Identification System (HMIS) that is an effort to inform employees about the various hazards presented by over 1500 raw materials used in the industry. ${ }^{61}$ Three kinds of hazards are highlighted in this system: health, flammability, and reactivity,

56. See National Institute of Occupational Safety and Health/Occupational Safety and Health administration, Occuational Health Guidelines for Chemical Hazards (Jan. 1981), for proposed standards for some 350 chemicals. NIOSH criteria documents, which should form the basis for regulation, have been prepared for some 97 substances.

57. National Institute of Ocgupational Safety and Health, National Occupational HaZARD SURVEY (May 1974) (looseleaf version).

58. Proposed in 46 Fed. Reg. $4412-36$ (1981); Final Regulation at 48 Fed. Reg. $53280-348$ (1983).

59. OSHA Draft Analysis, supra note 49 , at 9.

60. Whether OSHA has the power to impose requirements outside the workplace is unclear.

61. See National Paint Coatings association, NPCa in-Plant Hazardous Materials Identification System IMPlementation Manual (1981). 
each of which is associated with a particular color on the label. Degree of hazard is indicated on a five-tiered scale that ranges from zero to four, with zero the lowest hazard. Each raw material is rated on seven characteristics: oral toxicity, eye irritation, skin irritation, skin penetration toxicity, inhalation toxicology, sensitization potential (both skin and respiratory), and chronic effects. ${ }^{62}$ The overall health rating is simply the worst rating from any one of these categories. A fourth panel on each label describes the personal protection required for the substance, coding combinations of personal protection with a letter. Each employee must carry a wallet-sized card that shows the kinds of personal protection associated with each letter and also summarizes the hazard index.

Although relatively simple for the employee, the system depends on the availability of large amounts of information about each substance. Paint manufacturers would find the expense in generating and interpreting this information greatly reduced if shippers of the raw chemicals would provide it. Similarly, industrial users of paint will find their labeling burden reduced if they make use of the HMIS, but then they would have to apply it to nonpaint hazardous substances in their operations. The establishment of a labeling method anywhere in the system creates pressure to adopt it up and down the line. Adoption of different systems has the potential for creating confusion as well as waste of information resources. The HMIS system, for example, uses zero to indicate the lowest risk. This rating corresponds to the scheme in a widely-used system of voluntary standards developed by the National Fire Protection Association ${ }^{63}$ but contrasts with the Environmental Protection Agency (EPA) rating scheme, mandatory for pesticides, in which Toxicity Category I represents the highest hazard and Category IV the lowest hazard. ${ }^{64}$

In sum, many manufacturers have voluntarily undertaken labeling of hazardous substances within the workplace. Although there are many labeling schemes, some in use by only one company, the MCA-LAPI system is generally accepted for indicating acute hazards. Systems for labeling chronic hazards are not yet widely accepted, require generation of vast amounts of information in areas of continuing scientific uncertainty, and are far from standardized. Workers who move from factory to factory, therefore, must be retrained in the reading of labels as well as in learning new tasks. Concerned about the potential consequences of lack of worker information, OSHA has proposed a comprehensive labeling and employee training program, while some twelve states and localities have passed their own "right-to-know" laws incorporating different definitions of "hazardous" and a variety of labeling and information requirements. ${ }^{65}$ Labeling of occupational hazards is in flux.

62. Keller, Schaper, \& Johnson, A Hazardous Materials Identification System for the Coatings and Resins Industry, 1980 AMER. INDUS. HyGIENE Assoc. J. 901,903

63. National Fire Protection Association, Standard 704, Identification of Fire Hazards (1980); see also N.I. SaX, Dangerous Properties of Industrial Materials 246-47 (4th ed. 1975).

64. See 40 C.F.R. \& 162.10 (1982). The EPA "tox categories" do not appear directly on the label, but they are instrumental in determining which signal word does appear.

65. See, e.g., ME. Rev. Stat. AnN. tit. 7, \$§501-513 (1982); Tex. Rev. Civ. Stat. Ann. art. 4476-13 (Vernon 1982). 


\section{B. Transportation}

After manufacture, chemicals are transported. Since the passage of the Transportation of Explosives Act in 1908, ${ }^{66}$ vehicles carrying dangerous substances have been required to bear at least some warnings. The somewhat haphazard Congressional authorization of authority to administer labeling programs resulted very early in problems in labeling shipment containers and vehicles. In its 1948 Annual Report, the Interstate Commerce Commission (ICC) noted that its regulations, which called for a green diamond bearing the notation "DANGEROUS-COMPRESSED GAS" and nothing else, conflicted with requirements under The Federal Insecticide, Fungicide, and Rodenticide Act (FIFRA) that the word "POISON" in red and an antidote appear on containers of affected substances. ${ }^{67}$ The latter act also applied to more substances than did the ICC regulations.

One agency, the Department of Transportation (DOT), is now responsible for safety in transport. DOT requires placards on trucks and rail cars carrying hazardous materials and labels and other markings on small packages. The purposes of labels and placards are to reduce risk to handlers of the containers at either end and to speed appropriate response to accidental spills en route. Materials must also be packaged so that "[ $[\mathrm{t}]$ here will be no significant release of hazardous materials into the environment."68 The only signal words prescribed by DOT are the words "DANGEROUS" (to be accompanied by a red triangle), which must be placed on certain explosives and irritants, and "POISON," to be applied to categories denoted "Poison A" and "Poison B" and to fluorine. 69 Words indicative of particular hazards are often required to appear on signs of specified colors. Definitions of hazardous characteristics differ slightly from those used by other agencies. Complete labels for specific chemicals are prescribed in a ninety-five page table; ${ }^{70}$ additional optional labels are described in another table of similar length. ${ }^{71}$ Labels for transporting hazardous chemicals are simpler than those required for other purposes. Simpler labeling is appropriate since the transporter is not expected to be exposed to the chemical itself. The likelihood of exposure is reduced by nonlabel regulations for container construction and handling.

\section{In Use}

Final consumers of chemical products deliberately choose to enjoy the benefits of use. To make appropriate consumer decisions, however, they should be apprised of the risks entailed in that use. Although risks and benefits accrue to the same consumer, he has relatively little incentive to obtain information about any one product in part because he uses so many and in part because the information about each is complex. Labeling policy for end-use chemicals must balance accu-

66. Ch. 234, 35 Stat. 554 (1908) (current version at 16 U.S.C. $\$ 506$ (1982)).

67. Interstate Commerce Commission, Sixty-Second Annual Report of the Interstate COMMERCE COMMission - 1948, at 119-20.

68. 49 C.F.R. $§ 173.24(a)(1)(1981)$.

69. For "dangerous," see 49 C.F.R. $\S \S 172.506-521$ (1981); for "poison," see 49 C.F.R. $\S \S 172.506$

173.325 (1981). Note the continuation of the word "dangerous" from ICC regulations of fifty years ago!

70. 49 C.F.R. $\S 172.101$ (1981).

71. Id. § 172.102. 
racy against the need to reduce the amount of information in order to get the consumer's attention.

Once the 1906 Food and Drug Act established the principle of labeling of potentially hazardous products, Congress quickly extended labeling to another category of major importance to an agricultural society, namely, pesticides. ${ }^{72}$ The scope of regulation was expanded by the enactment of the 1927 Caustic Poisons Act. ${ }^{73}$

The most general statement of a policy of labeling hazardous chemicals for consumer use came with the passage of the Federal Hazardous Substances Act (FHSA) ${ }^{74}$ in 1960 . The act was a response to the rapid growth in the number of chemicals commercially available and to the deaths of some 500 children annually from swallowing those chemicals. ${ }^{75}$ The statute incorporates characteristics of hazardousness-flammability, corrosiveness, sensitizers, etc.- that are clearly derived from the MCA-LAPI definitions and the regulations drawn from these definitions and promulgated by the Department of Agriculture under FIFRA. ${ }^{76}$ For example, the numerical distinctions between "highly toxic" and "toxic," and between "extremely flammable" and "flammable," are identical with the earlier formulations. FHSA labels use four signal words: "POISON," "DANGER," and "WARNING" or "CAUTION." As with the predecessor regulations, the word "POISON" with the skull and crossbones is required when a substance is highly toxic. ${ }^{78}$ The signal word "DANGER" is required for products that are highly toxic or corrosive, or extremely flammable ${ }^{79}$ (these terms are defined quantitatively in the statute), ${ }^{80}$ and it is usually followed by a description of the hazard. Finally, "WARNING" and "CAUTION" are used interchangeably for other hazards. ${ }^{81}$ In most cases, the particular ingredient that causes the hazard is to be named. ${ }^{82}$

The FHSA, along with the Poison Prevention Packaging Act ${ }^{83}$ and the Flammable Fabrics Act, ${ }^{84}$ is now enforced by the Consumer Product Safety Commission (CPSC). ${ }^{85}$ The Poison Prevention Packaging Act allows the agency to require child-proof caps. This act is a response to the clear inability of certain groupshere, children - to respond to labeling since many are unable to read. The Flammable Fabrics Act allows standards to be set to reduce the likelihood of injury from fires in products such as clothing and upholstery.

72. The Insecticides Act, Pub. L. No. 61-152, 36 Stat. 331, 333 (1910) (repealed 1947). This article uses the term pesticides to cover insecticides, rodenticides, fungicides, and other related substances.

73. Ch. 489, 44 Stat. 1407 (1927) (repealed 1960).

74. Pub. L. No. 86-613, 74 Stat. 372 (1960) (current version at 15 U.S.C. $\$ \S 1261-1276$ (1982)).

75. H.R. ReP. No. 1861, 86th Cong., 2d Sess., reprinted in 1960 U.S. Code ConG. \& AD. NEwS 2833.

76. See Table 2.

77. 15 U.S.C. $\S 1261(\mathrm{p})(1)(1982)$

78. Id. $\S 1261(\mathrm{p})(1)(\mathrm{H})$.

79. Id. $\$ 1261(\mathrm{p})(1)(\mathrm{C})$.

80. Id. $\S 1261(\mathrm{~h})(1),(\mathrm{i}),(l)(1)$

81. Id. $\S 1261(\mathrm{p})(1)(\mathrm{D})$.

82. Id. $§ 1261(\mathrm{p})(1)(\mathrm{B})$.

83. 15 U.S.C. $\S \S 1471-1476$ (1982).

84. 15 U.S.C. $\$ 1191$ (1982).

85. See id. $\S 2054$; see also id. $\S 2053$ (establishing the CPSC). 
In addition to enforcing the general requirements of these three acts, the CPSC is empowered to regulate products to ensure safety for consumers by imposing standards on manufacturing or performance, ${ }^{86}$ by requiring labels, ${ }^{87}$ by certification, ${ }^{88}$ and, if none of these remedies is adequate, by banning. ${ }^{89}$ Since each product is considered separately, labels, if prescribed, are determined individually and prescribed in the regulation for each substance. Perhaps the most famous label is the one designed for lawnmowers, which pictures a finger nearly severed by a blade with an arrow pointing to the place into which the user is not to insert his extremities.

One very important end-use for chemicals is in pesticides, which are regulated by EPA. Pesticides remain a separate category of regulated products and have different labeling requirements than those for other chemicals because they differ from other chemicals in the following ways:

(1) The same products are used by consumers and by workers (in agriculture);

(2) Pesticides are intended to kill things, so reduction of risk below a certain level would render the products useless;

(3) Risks of use accrue to the environment and are not readily contained; 90 and

(4) As with drugs, pesticide labels serve as the indications of the conditions for product registration.

Pesticide labels must therefore serve a variety of regulatory purposes.

To register a pesticide, the manufacturer must submit large volumes of scientific test data in support of a proposed label. These data detail specific crops and pests for which the substance is to be used and appropriate methods of application for each use; they also provide information about contents, precautions, protective clothing, antidotes, and re-entry periods, which are the amounts of time that must elapse before people may go back into a field where the pesticide has been applied. Most of the data submitted will not be placed directly on the label but will be used by EPA to assess the effects of using the product as indicated on the proposed label. Typically, after receiving an application for registration, EPA requests additional data and also suggests label revisions. At least one new pesticide label underwent 300 revisions before it was approved for the first time. ${ }^{91}$

The primary guide to risk on pesticide labels is the "signal word." Since 1950, EPA has tied notification of danger to "toxicity categories."92 These are quantitative measures of possible injury, very similar to those developed by MCA-LAPI, in which each successive category represents toxicities approximately one-tenth of the preceding category. The most injurious is Category I, which requires use of the signal word "DANGER." The nature of the hazard and appropriate cautionary

86. Id. $\S 2056(\mathrm{a})(1)$.

87. Id. $\S \S 2056(\mathrm{a})(2), 2063(\mathrm{a})(1)$.

88. Id. $\S 2063(\mathrm{a})(1)$.

89. Id. $\$ 2057$.

90. For a nonpesticide environmental hazard that must be labeled, see the regulations for PCB's at 40 C.F.R. $\$ 761.40$ (1982).

91. Interview with the manufacturer. (The manufacturer is unidentified in order to respect a request for confidentiality.)

92. 7 C.F.R. $§ 162.116$ (Supp. 1952). 
statements must accompany the signal word. If the substance is assigned to Category I by reason of its oral, inhalation or dermal toxicity, the additional signal word "POISON" must appear along with the skull and crossbones. Substances falling in Category II are marked with the word "WARNING," while substances in the two least dangerous categories are indicated by the same signal word "CAUTION"; labels on Category IV (lowest hazard) pesticides do not need precautionary statements. Pesticides in all categories must bear the child hazard warning. Like the occupational warnings they are related to, labels based on toxicity categories address only acute hazards.

Another guide to risk on a pesticide label is the indication "restricted use." The 1972 amendments to FIFRA provided for a two-fold classification of pesticides. ${ }^{93}$ As presently interpreted, restricted use pesticides may only be applied by or under the direct supervision of a "certified applicator" who has met his state's standards. Thus restricted use is one means of distinguishing between pesticides suitable for household consumers and those appropriate only in the "workplace"; at the same time, the designation should help protect worker health and safety by limiting applicators to those properly trained.

Risks to the environment cannot be limited by means of the "restricted use" designation, which is believed to have a very limited effect on the amount consumed. These risks are controlled by restricting uses rather than users and are reflected on the label in the lists of acceptable crops and pests. Thus the outcome of a Rebuttable Presumption Against Registration (RPAR) proceeding by EPA has more typically been a limitation on a product's permitted uses than outright banning.

Pesticide labels are probably the longest of all labels, incorporating human and environmental risk statements, detailed instructions for use, and limitations on uses and users. The need for this complex arrangement is due to the simultaneous existence of at least two kinds of market imperfections: the production of externalities in consumption and the lack of information. Since users are decentralized and have few incentives to acquire or use information about the negative spillovers to the environment from their use, regulation of them is difficult. In the similar situation with automobiles, the solution has been to require manufacturers to install pollution control devices. The analogous action for pesticides is to try to reduce use to a level consistent with acceptable environmental effects; determining how to reduce use as little as possible requires information not usually available. The effect of the registration procedure is therefore to force manufacturers to produce information that permits the agency to reduce externalities of use efficiently through limitations on consumption indicated on the product label.

\section{Assessment of Labeling Regulations}

Table 2 (see APPENDIX) provides a comparison of some indicative hazard labeling standards for four agencies and two voluntary standard-setting organizations. It thus serves as a summary of the preceding discussion. It shows that while

93. Pub. L. No. 92-516, 86 Stat. 981 (1972) (current version at 7 U.S.C. $§ 136 a(d)(1)(A)(1982)$ ). 
standards of acute risk (toxicity, flammability) are influenced by the old MCALAPI definitions, there is still a range of physical properties indicated by the same label terms. The table illustrates a wider range of differences in the means used to indicate risk: signal words, colors, and numbers are used inconsistently. Not only do risk standards vary across agencies, but the way in which the same risk information is imparted varies as well. Furthermore, labels in the workplace tend to contain less information than those on many consumer products, especially pesticides, despite the fact that more risk is likely to be averted per unit of information on a workplace label.

The ways in which labels indicate risk range from the direct to the obscure. The most direct warnings on labels indicate acute hazards, which are identified by name (toxic, corrosive) along with a statement defining precautionary behavior that amplifies understanding of the risk, such as "do not breathe." OSHA has provided for similarly direct warnings for the chronic hazards of a few chemicals that must be labeled "CANCER HAZARD."94 When applicable, pesticides may also be labeled to indicate short or long term environmental hazards, but for direct warnings, emphasis has been on the more readily measured and compared aspects of risk evidenced in acute effects.

A somewhat less direct indication of risk level is the use of signal words. Unfortunately, interpretation of risk depends on knowing what each word is intended to signal. An informal survey of friends suggests that laymen do not know that "danger" warns of a more severe hazard than "warning" or "caution". Some additional ambiguity arises from the differences between the three-tier use of signal words by EPA and the two-tier use under FHSA.

Even less direct is the inference of riskiness (and the nature of risk) from information about protective clothing. To use this information, it is necessary to know that some substances do not require the use of protective clothing, and to understand how the various protective devices are to work. Similarly, it is possible to infer hazard from restrictions on users and uses. A pesticide or drug indicated for very few uses is probably quite risky indeed. Less dangerous but worth noting are substances marked for use by certified applicators or physicians only. Restricted use thus constitutes a new regulatory option between banning and labeling; its appearance on a label is essentially notification that a nonlabel form of risk regulation has been applied.

The overall effect of these labeling conventions is that the user must come to the label already in possession of an abundance of information. The experience with signal words and, in another area, nutrition labels suggests that many consumers do not possess such information. ${ }^{95}$ Furthermore, risk labels focus on providing information about short term severity at the expense of long term severity and of probability. The user is assumed to understand the benefits of use, an assumption made more reasonable by government assurance of the accuracy of

94. See, e.g., 29 C.F.R. $\$ 1910.1018$ (p)(3) (1982) (requirements for labeling of inorganic arsenic).

95. Division of Consumer Studies, U.S. Food \& Drug Administration, fda Consumer Nutrition KNOWLEDGe SURVEy, RePORT 2, 1975 (1976). 
label information concerning effectiveness and appropriate use, as well as by government regulation of advertising.

Finally, the table suggests that there are two rather different kinds of labels: some triggered by a hazard and others triggered by a specific chemical. The idea that the need for a label should be triggered by the existence of a certain level of hazard was explicitly articulated by the early MCA-LAPI Committees. Many of the label designations that are tied to hazards, EPA signal words, for example, have that standard in their ancestries. OSHA's labels, on the other hand, and to a large extent DOT's, are made for each chemical. Although this difference has some implications for regulatory efficiency and consistency, it is overwhelmed by the need in both cases to test and measure each chemical with respect to each potentially risky characteristic. Thus labeling remains basically a substance-by-substance form of regulation, which is inherently burdensome when the substances to be considered number in the hundreds of thousands. Given the number of chemicals affected, the haphazard way in which labeling requirements gradually built up over the years, and the number of agencies involved in overseeing labeling programs with diverse purposes, it is not surprising that labeling of chemicals entails composing thousands of different labels, or that the same chemical must be labeled differently at different stages in its life.

\section{V}

\section{TOWARD a UNIFIED LABEling SYSTEM}

The characteristics of risk-probability, magnitude and severity-determine that a successful risk control program reduces either the number of people or the land or water area affected or the seriousness of the consequences of undertaking a particular act. Labeling is designed to accomplish these purposes by informing people (who would otherwise not know) that a risk exists and informing people (who do know that there is a risk) how to reduce or avoid it through proper use or preventive measures. Labeling may also result in a more efficient allocation of social resources by allowing individuals who are willing to accept a risk to do so, rather than removing the risk for everyone by prior imposition of nonlabeling regulatory standards. Indeed, the relatively low level of control inherent in a labeling regulation has made it a politically attractive alternative. The frequency and diversity of cases in which it has been required help to account for the multiplicity and inconsistency of label requirements.

The effectiveness of labeling as a risk control strategy assumes that people will read, understand, and act on the information presented. Although there is evidence from market research and from psychological studies that labels are partly effective, much of the evidence suggests a need to question this assumption. After reviewing some of this evidence in order to suggest requisites for a sound labeling strategy, I propose a new labeling system that meets these requirements.

\section{A. Conditions for Label Effectiveness}

Some intended recipients of label information do not read or use labels at all. There are four explanations for this: 
1. They cannot read. There are some 1.25 million illiterates in the United States; 96 in addition, there are at least an equal number of people who are functionally illiterate, who read a language other than English, ${ }^{97}$ or who simply have not yet learned to read. As previously mentioned, the use of child-proof caps is a response to the latter problem.

2. They cannot understand the label. This may occur from failures of the users or failures of the labels. As previously suggested, comprehension of many hazard labels requires the user to bring with him to the label a significant amount of information already obtained; for example, to use ingredient labels, the reader must know the relevant characteristics of the ingredients. People without this information will not understand the label. The elderly have been shown to be especially likely to fail to comprehend label information. Furthermore, people do not store and retrieve information literally, so they often mistakenly infer information not presented. ${ }^{98}$ As already noted, many possible deficiencies exist in labels, including deliberate use of partial truths or overly technical wordings. The lack of consistency in label formats and in indications for similar risks also reduces comprehension. One investigator found that approximately two-thirds of a large sample of health and social services leaflets designed for use by the general public would be beyond the comprehension of more than half the population. ${ }^{99}$

3. They feel they do not need the label. Several studies show that consumers believe that the fact that a product is labeled (or marketed) is itself evidence of safety; with drugs, consumers assume that the doctor would not prescribe an unsafe drug. Consumers also have more confidence in an industry that makes open disclosure of basic facts, even though they may not use those facts in making purchasing decisions. ${ }^{100}$

4. They simply ignore labels. Specific labels, such as the cigarette warning, may become too familiar, or there may be too many labels everywhere. ${ }^{101}$

More often than ignoring labels altogether, readers appear to use only part of label information. A phenomenon often called "information overload" explains this tendency. As the name suggests, overload means that the individual is no

96. U.S. Bureau of the Census, Statistical Abstract of the United States 19815,143 (1981). Page 143 shows .5\% of the population over 14 as illiterate; the population is estimated at 225.1 million in 1979 on page 5.

97. Some agencies require some labels to be provided in Spanish. See, e.g., 21 C.F.R. § 201.16 (1982); 40 C.F.R. $\S 170.5$ (1982).

98. Cf. W. Wilkie, How Consumers Use Product Information: An Assessment of Research in Relation to Public Policy Needs 49 (1973).

99. Ley, Practical Methods of Improving Communication, in Product Labeling and Healty Risks 135 (Banbury Report No. 6, 1981). The latter summarizes additional references supporting the general conclusion that health communications are often poorly understood. On inferring, see Harris, supra note 18.

100. J. Gibson, Medication Law and Behavior 88-89 (1976); Daly, The Response of Consumers to Nutrition Labeling, $10 \mathrm{~J}$. CONSUMER AFF., Winter 1976, at 170-79; Lenahan, Consumer Reaction to Nutritional Labels on Food Products, $7 \mathrm{~J}$. Consumer AFF., Summer 1973, at 1-12; Parkinson, The Role of Seals and Certificalions of Approval in Consumer Decision-Making, $9 \mathrm{~J}$. CONSUMER AFF., Summer 1975, at 1-14.

101. Federal Trade Commission, Staff Report, Advertising for Over-the-Counter Drugs 72-74 (May 1979); Johnson, The Information Processing Analysis of Product Labels, in Advances IN Consumer ReseARCh VII 724, 724-28 (J. Olson ed. 1980); McGuire, The Communications-Persuasion Model and Heallh-Risk Labeling, in Product Label.ing And Health Risks 99, 99-122 (Banbury Report No. 6, 1981); James Sneed, Statement of FTC Staff to Congress, reported in Austin American Statesman, May 27, 1981 , at A8. 
longer able to process new information because he is still absorbing other information. ${ }^{102}$ In fact, there is evidence that as additional information is provided, consumers whose information-using capacities have been exceeded tend to make poorer choices but also tend to feel better about them. Thus too much information may be doubly deceptive. ${ }^{103}$

A 1978 Food and Drug Administration (FDA) study of food labels, for example, found that only six percent of the respondents claimed to read the entire label, while sixty-four percent said they read and used at least part of the label. It is interesting to note that almost two-thirds of the respondents said that they read the calories and cholesterol (risk) portion of the label rather than the vitamins and minerals (benefit) portion. ${ }^{104}$ The same phenomenon may occur in the use of over the counter (OTC) drug labels. This finding has important policy implications since it suggests that consumers will read either product identification information or warnings and other product use information, although both are necessary for proper consumer evaluation. ${ }^{105}$ An inconsistent labeling system also contributes to information overload and to the use of only parts of labels because it requires consumers to become familiar with so many different labels. Consumer use of each product-and therefore the associated risk-is sufficiently small that it is not worthwhile to invest resources in obtaining full risk information about each one.

Although this brief review cannot do justice to the extensive literature on consumer understanding and use of labels and hazard information, it is sufficient to suggest several characteristics of labels and other systems of providing information that will increase the likelihood that users will indeed be able to evaluate risks. Labels should be:

- arresting (to increase initial awareness),

-simple (to increase comprehension),

- consistent (to increase comprehension), and

-salient (to increase utilization). ${ }^{106}$

At the same time, enough information should be provided so that the user can form a reasonably accurate impression of the risks entailed in use. Therefore, labels should also present information hierarchically to allow users to obtain appropriate amounts of information and to reduce information overload.

102. See Bettman, Issues in Designing Consumer Information Environments, 2 J. Consumer RESEARCH 169, 169-77 (1975); Kanouse \& Hayes-Roth, Cognitive Considerations in the Design of Product Wamings, in PRODUCT LABEling AND HeAlTh Risks 147 (Banbury Report No. 6, 1981).

103. Frenchy \& Barksdale, Food Labeling Regulations: Efforts Towards Full Disclosure, J. MARKETING, July 1974 , at 14,17 (discussing results of research by Jacoby). Not all specialists in consumer research accept Jacoby's findings or the general notion of information overload. See Scammon, Information Load and Consumers, 4 J. Consumer Research 148 (1977).

104. Food and Drug Administration, 1978 Consumer Food Labeling Survey (mimeo).

105. See generally Grahn, Consumer Information Processing of OTC Drug Label Information, in ADVANCES IN CONSUMER Research VII 633, 633-38 (J. Olson ed. 1980).

106. Although a government cannot ensure that readers act upon labels without detailed and probably inappropriate enforcement efforts, it still has an obligation to ensure that information is presented in such a way that the likelihood of use is maximized. 


\section{B. Symbols for Hazard Labeling}

The present system of labeling for risk control should be refined to provide three levels of information, with the simplest and most general level a uniform set of hazard symbols. This system would increase the accessiblity and utility of hazard information and would make it consistent at one level, without sacrificing the flexibility of the present system to tailor label information to the specific requirements of each substance.

Information can be thought of as hierarchical. Simple, general statements can be refined and made more accurate through provision of additional information. Figure 2 illustrates this principle. The importance of considering information in this way can be seen in Senator Edmund Muskie's request for a " 'one-armed" scientist" who does not always answer questions with "on the one hand . . ., but on the other hand. . . ."107 The policymaker seeks a general, if not absolutely accurate, piece of information that will allow him to act.

Label information should be presented in the same way. The saliency of the information should be immediately apparent. Those for whom the information is relevant will then be able to read further to obtain a more detailed version. The present labeling system provides both levels of information mixed together, thereby discouraging use. Still more detailed information should also be available, although not on the label itself, for those for whom the benefits of obtaining it are especially high. The growing system of Material Safety Data Sheets can provide this third level of detail.

The first, most general level of label information that allows users to screen for saliency should be conveyed by a system of symbols. Symbols have been used for thousands of years to convey information. ${ }^{108}$ Their use has expanded greatly as a result of the expansion of international trade and of science. They meet the requirements of labels outlined above because symbols are more arresting than words and are more rapidly comprehended than words by the literate, and, at the same time, they are accessible to the illiterate.

The ability of symbols to grab the attention has been shown indirectly by several studies of highway signs in which symbolic signs are found to be more visible under conditions of poor visibility. ${ }^{109}$ Speed of recognition is also much higher for symbols than for words, which contributes to their ability to obtain attention. ${ }^{10}$ It is especially important that reaction time is found to be faster for warning signs than for other kinds of signs. ${ }^{11}$ Symbols are also more accessible to individuals who do not read. Although literacy and training increase understanding of sym-

107. Slovic, Fischhoff \& Lichtenstein, Informing People About Risk, in Product Labeling and Health Risks 165, 169 (Banbury Report No. 6, 1981).

108. On the origins of writing in symbols some six thousand years ago, see Schmandt-Besserat, The Earliest Precursor of Writing, $238 \mathrm{SCl}$. AM., June 1978, at 50.

109. See B.L. Collins, The Development and Evaluation of Effective Symbol Signs $11-12$, 19, 29-31, 45 (NBS Building Science Series 141 1982).

110. Dewar \& Ells, Comparison of Three Methods for Evaluating Traffic Signs, 503 TRANSP. RESEARCH REC. 38 (1974); Janda, Effectiveness of Various Highway Signs, 14 Highway Research BOARD PrOCS. 442 (1934). See generally B.L. Collins, supra note 109.

111. Dewar \& Ells, supra note 110 , at 38-47; Janda, supra note 110 , at 442-47. 


\section{A HIERARCHY OF HAZARD INFORMATION}

1. Pictorial Symbol General:

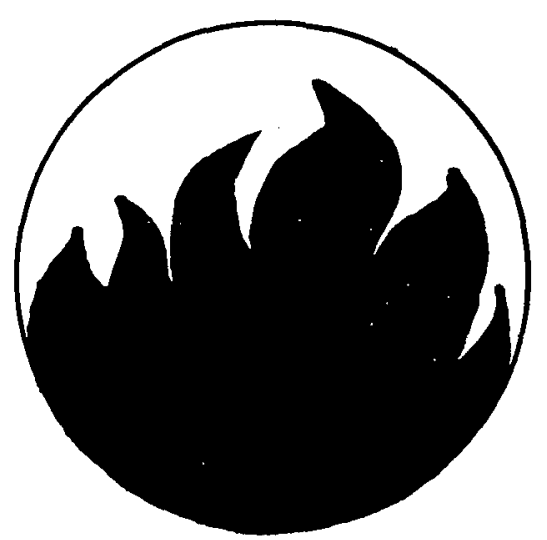

2. Specific Hazard Information:

\section{DANGER! EXTREMELY FLAMMABLE CAUTION}

\section{LONG-TERM HEALTH HAZARD}

Keep container tightly closed.

Do not expose to temperatures above $50^{\circ} \mathrm{F}$.

Avoid contact and breathing dust.

Wash skin and clothing after exposure.

3. Detailed Risk Description:

This product is a stereoisomer of $\mathrm{xxxx}$.

Flashpoint: $75^{\circ} \mathrm{F}$

Solubility: in $\mathrm{g} / 100 \mathrm{ml}$. at $25^{\circ}$

LD50 (oral): $25 \mathrm{mg} / \mathrm{kg}$ in rats $25 \mathrm{mg} / \mathrm{kg}$ in monkeys

Teratogenic effects: hamsters/oral $/ 5 \mathrm{mg} / \mathrm{kg} 8$ days

Occupational exposure: spraying $2-18 \mathrm{mg} / \mathrm{hr}$

4. Referral to Full Physical and Toxicological Information:

Further information about this product can be found in CHEMNET data base, Substance \#25-0123. 
bols, direct pictorial representations of concepts are highly accessible to most groups. ${ }^{112}$ A study of agricultural workers in the United States suggests that literacy in any language is an aid to symbol understanding, while confirming that even the illiterate can understand and use some labels bearing pictorial symbols. ${ }^{113}$

Design of symbols to ensure understanding is not easy. ${ }^{114}$ Furthermore, understanding of symbols is enhanced by repetitive exposure and by training in their meanings. For these reasons, it is desirable to develop a consistent set of symbols for hazards that could be taught in schools and used throughout adult life, just as schools impart other forms of safety training, including response to fire and identification of poisons with the new symbol, "Mr. Yuck."

Since 1970, Canada has used a consistent system of hazard symbols for consumer products. ${ }^{115}$ Symbols were chosen for hazard warnings in part because Canada has two national languages. The system uses three different shapesoctagon, diamond, and upside-down triangle - to represent three different hazard levels, corresponding to the signal words "danger," "warning," and "caution."116 Four pictorial symbols indicating the nature of the primary hazard are inserted into these shapes; symbols are designated for poison, corrosive, flammable, and explosive substances. ${ }^{117}$ Seven years after their introduction, the symbols were found to be partially effective; eighty percent of respondents in a survey recognized the poison and flammable symbols, while slightly under half recognized the other two. Significantly, correct identification of all symbols is highest among the youngest age group. ${ }^{118}$ This suggests the importance of supplementing a symbol system with education programs in schools.

Costs of implementing the system proposed here are kept to a minimum because labelers do not have to develop their own systems and because, at least at the outset, the new symbols are just added on to existing labels. Full agency review of labels is not necessary. The purpose of symbols in this initial label reform is to catch the attention of users and inform them that they may require additional information. The symbols are not intended to provide full risk information. Thus a picture of a person gasping in a mist might warn someone who was about to spray that he should read further, while someone simply transporting the closed container would handle it with care but would not read full label details.

Benefits of the proposed system are significant. Since the existing labels are left largely unchanged, their responsiveness to the requirements of different substances and industries are retained. The addition of symbols, however, increases the utility of those labels by increasing the likelihood that they are read and used. One of the most important contributions of a system of symbols is its consistency. At present, it is only in the case of workers that the costs of training in the proper

112. See generally B.L. Collins, supra note 109

113. E. Howitt \& C. Moore, Internalizing Health Effects of Pesticides 9-11 (unpublished manuscript).

114. See generally B.L. ColliNs, supra note 109.

115. Hazardous Products Regulations, Consol. Regs. Can., ch. 926, sched. III (1978).

116. Id.

117. Id.

118. Contemporary Research Centre Limited, A Study on Awareness and Identification of Hazardous Product Symbols (Jan. 1977) (unpublished manuscript). 
use of labels are clearly exceeded by their benefits. However, if a consistent set of symbolic labels were in use, it would be worthwhile to train all citizens in their meaning. At the same time, it would reduce training costs for workers, who would come to the job already knowledgeable about some aspects of using potentially hazardous substances. Finally, those costs measured in reductions of health and safety of users are minimized by avoiding the probability that people familiar with other inconsistent labeling systems will unintentionally misuse a substance. ${ }^{119}$

Some label users might require even more information than is available on the label. This is being made available through Material Safety Data Sheets, which are increasingly in use for occupational hazards. Such sheets could be kept on file in libraries to supplement existing, harder to use reference works on the proper handling and possible side effects of chemicals. Public access to computer data banks will also allow consumers to obtain more detailed information about substances especially important for them. One form of public access is now in place in various telephone hotlines which in turn make use of these data banks. ${ }^{120}$

\section{VI}

\section{CONCLUSION}

Government regulations that require producers to provide information about the risks of their products through labels constitute one of the most prevalent forms of regulation. Virtually all chemicals must be labeled at some point during their life cycles; most must be labeled throughout, sometimes with different or conflicting kinds of labels. Since the efficacy of labels as a risk control device depends on their being understood and used by readers, existence of a multiplicity of labeling systems undermines the purpose of the labels. A comprehensive revision of labeling programs would increase emphasis on long-term risks, standardize labels, ensure availability of more detailed information to anyone for whom it is germane, and supplement labels with education and training programs that enhance their utilities. These goals can be achieved in a more limited fashion through a much less comprehensive program requiring a consistent system of symbolic labels to be applied to all products now labeled, consistent with and summarizing current labeling.

119. Another case in which consistency can reduce social costs is considered in W. Grubb, M. Humphries \& D. Whittington, The Use (and Abuse) of Cost-Benefit Analysis in the Federal Government: The Implementation of Executive Order 12,291 at 27-29 (Oct. 29, 1982) (unpublished manuscript presented at the 1982 annual meeting of the Association for Public Policy Analysis and Management in Minneapolis, Minn.).

120. Two examples of such hotlines are CHEMTREC, the Chemical Transportation Emergency Center in Washington, D.C., which provides information about appropriate action for specific chemicals involved in transportation accidents, and the Texas Pesticide Hazard Assessment Project in San Bonito, Texas. 

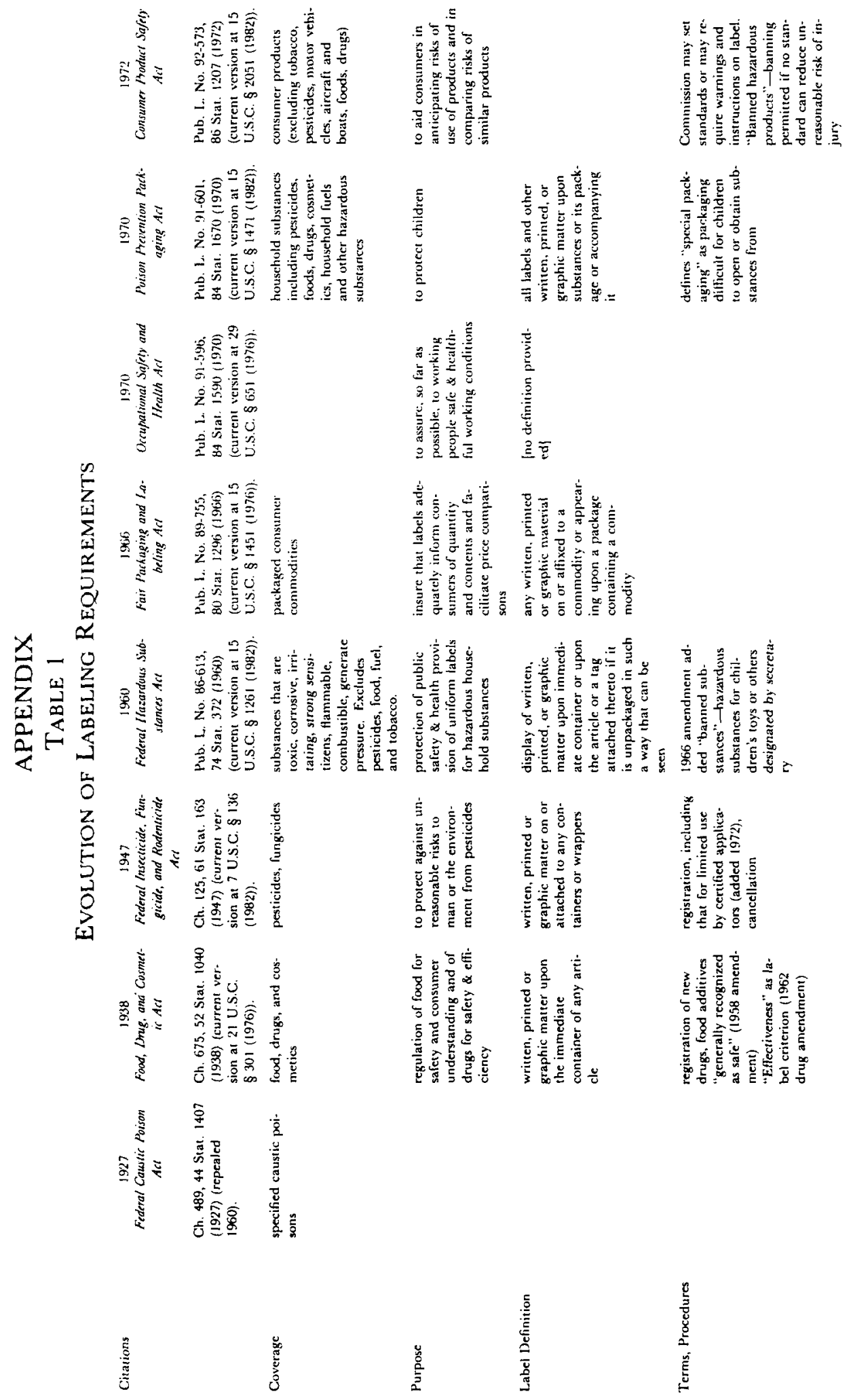


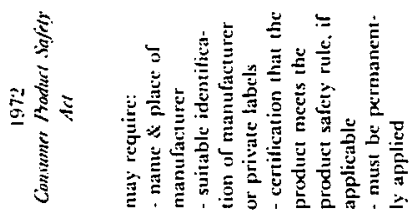

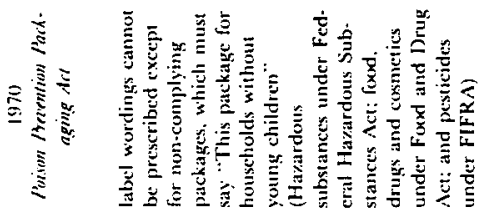

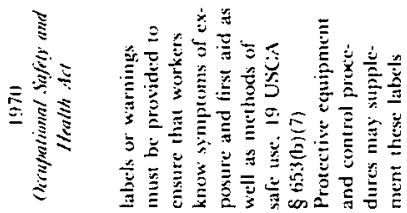

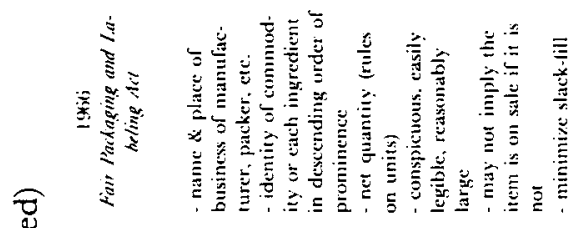

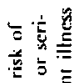

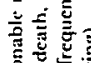

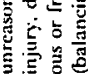

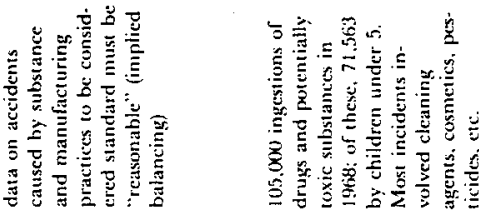

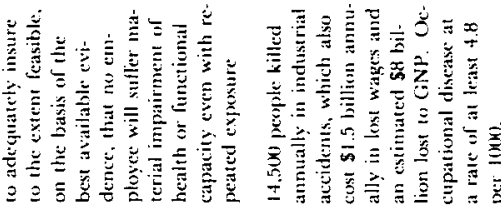
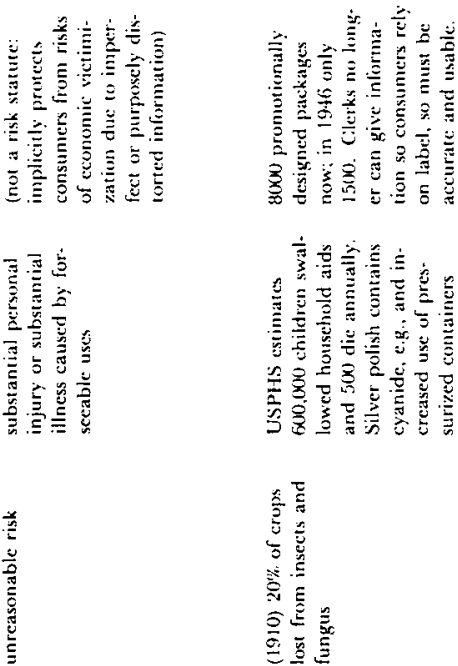

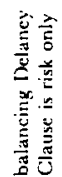

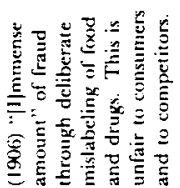

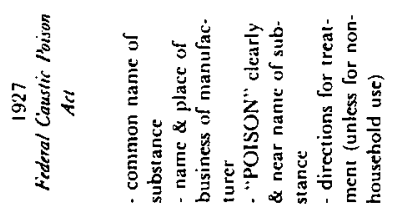

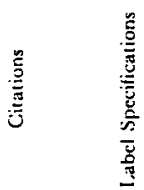

亮

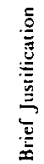




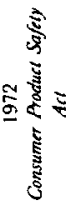

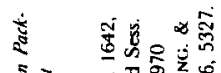

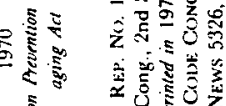

2

है

촐

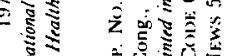

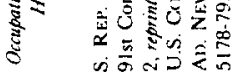

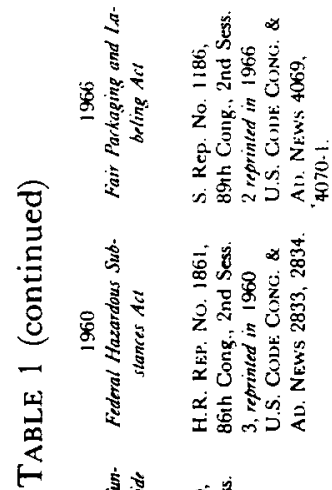

है

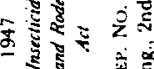

ริ

恼

密琶总

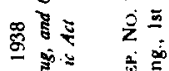

है.

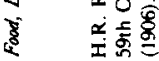

รู

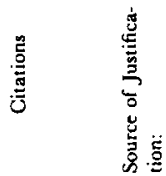




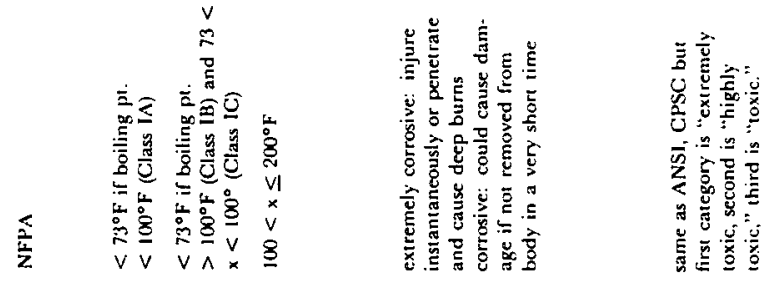

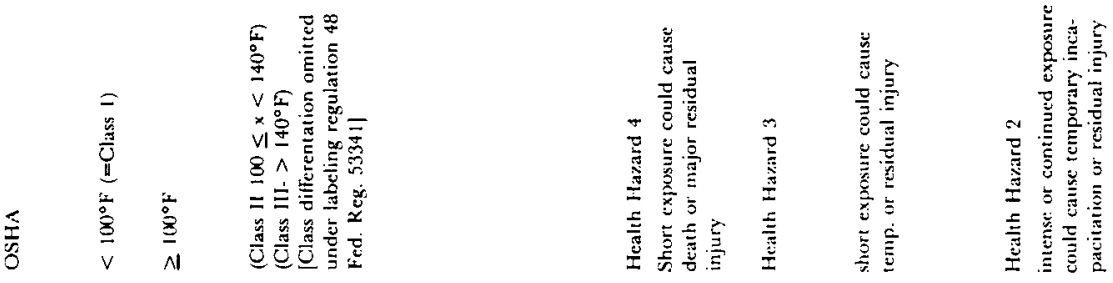
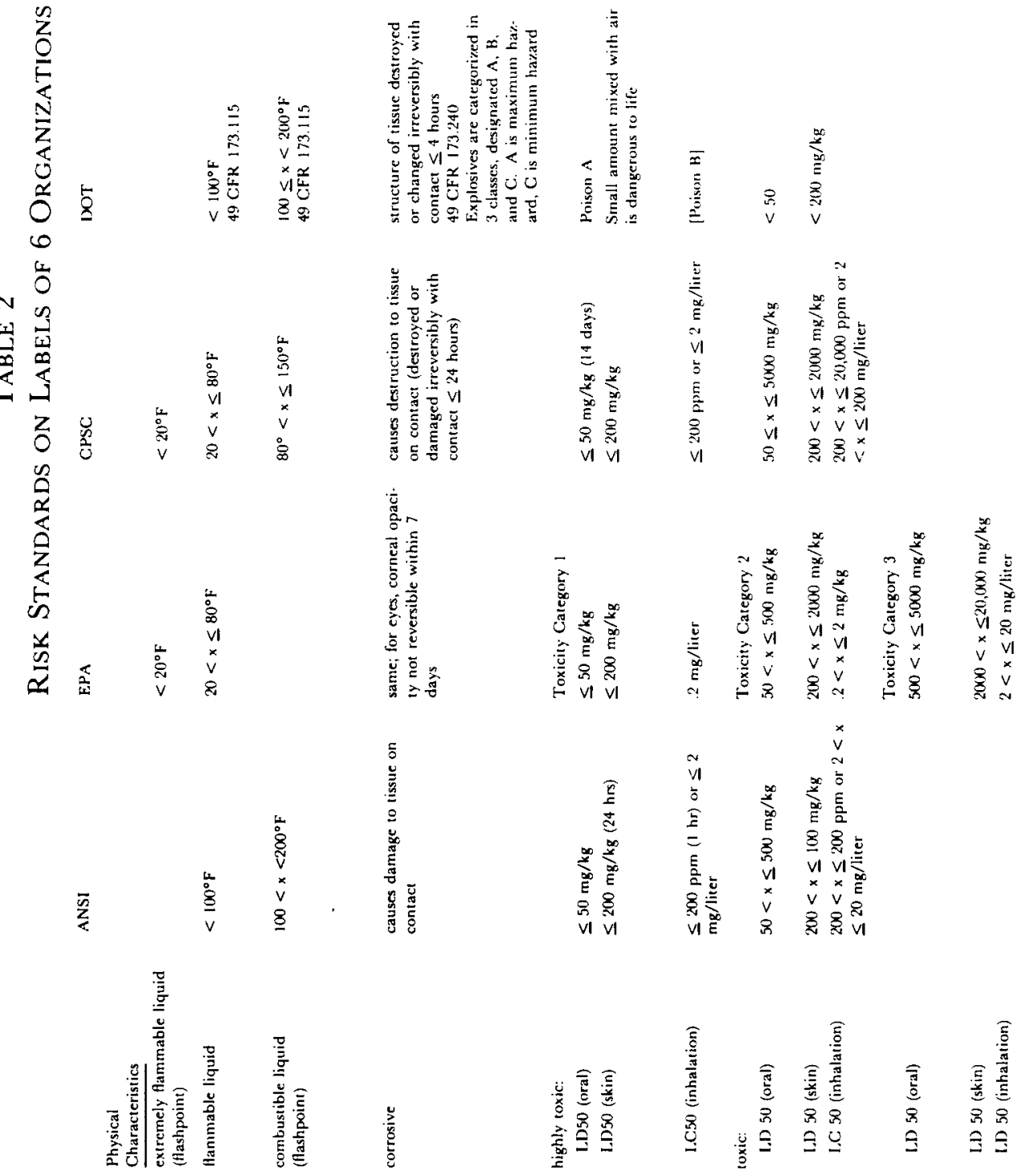

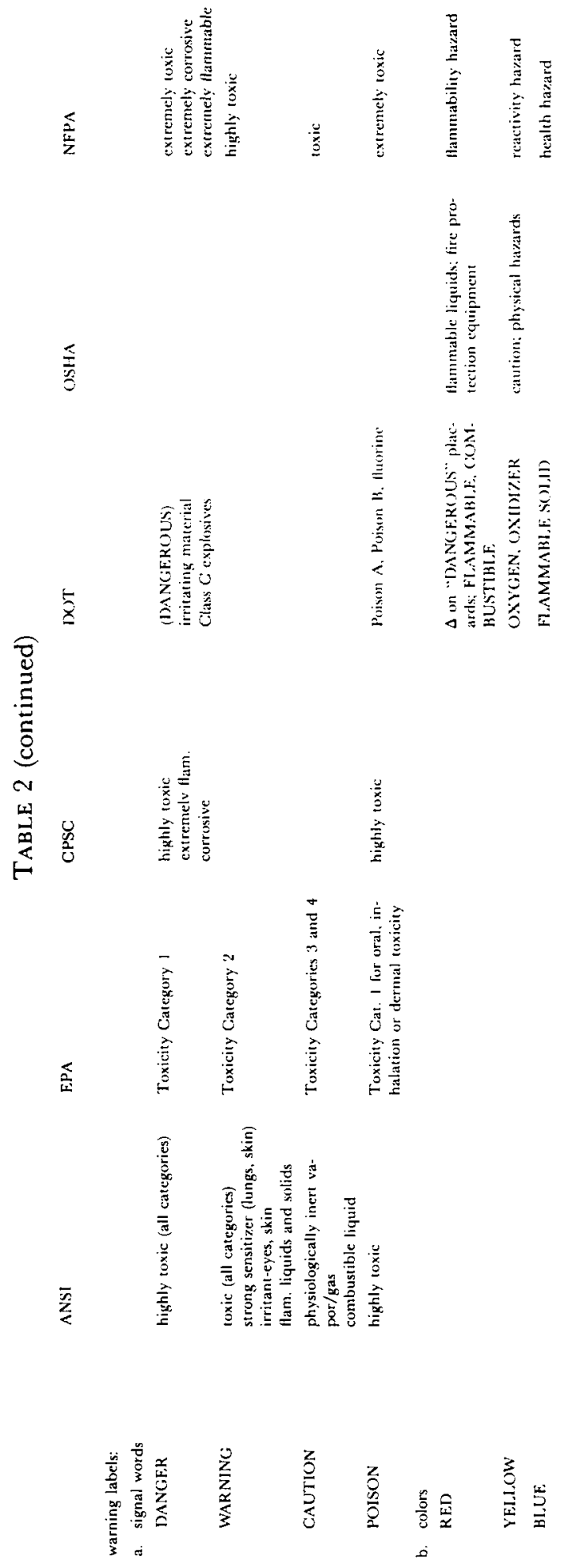